\title{
Cell-type specific short-term plasticity at auditory nerve synapses controls feed-forward inhibition in the dorsal cochlear nucleus
}

\author{
Miloslav Sedlacek ${ }^{\dagger}$ and Stephan D. Brenowitz * \\ Section on Synaptic Transmission, National Institute on Deafness and Other Communication Disorders, National Institutes of Health, Bethesda, MD, USA
}

\section{Edited by:}

R. Michael Burger, Lehigh

University, USA

Reviewed by:

Matthew James McGinley, Yale

University School of Medicine, USA

Michael Hideki Myoga,

Ludwig-Maximilians-Universität

München, Germany

*Correspondence:

Stephan D. Brenowitz, Janelia Farm Research Campus, Howard Hughes Medical Institute, 19700 Helix

Drive, Ashburn, VA 20147, USA

e-mail: brenowitzs@janelia.hhmi.org

${ }^{\dagger}$ Present address:

Miloslav Sedlacek, Laboratory of Cell Structure and Dynamics,

National Institute on Deafness and Other Communication Disorders,

National Institutes of Health,

Bethesda, MD, USA
Feed-forward inhibition (FFI) represents a powerful mechanism by which control of the timing and fidelity of action potentials in local synaptic circuits of various brain regions is achieved. In the cochlear nucleus, the auditory nerve provides excitation to both principal neurons and inhibitory interneurons. Here, we investigated the synaptic circuit associated with fusiform cells (FCs), principal neurons of the dorsal cochlear nucleus (DCN) that receive excitation from auditory nerve fibers and inhibition from tuberculoventral cells (TVCs) on their basal dendrites in the deep layer of DCN. Despite the importance of these inputs in regulating fusiform cell firing behavior, the mechanisms determining the balance of excitation and FFI in this circuit are not well understood. Therefore, we examined the timing and plasticity of auditory nerve driven FFI onto FCs. We find that in some FCs, excitatory and inhibitory components of FFI had the same stimulation thresholds indicating they could be triggered by activation of the same fibers. In other FCs, excitation and inhibition exhibit different stimulus thresholds, suggesting FCs and TVCs might be activated by different sets of fibers. In addition, we find that during repetitive activation, synapses formed by the auditory nerve onto TVCs and FCs exhibit distinct modes of short-term plasticity. Feed-forward inhibitory post-synaptic currents (IPSCs) in FCs exhibit short-term depression because of prominent synaptic depression at the auditory nerve-TVC synapse. Depression of this feedforward inhibitory input causes a shift in the balance of fusiform cell synaptic input towards greater excitation and suggests that fusiform cell spike output will be enhanced by physiological patterns of auditory nerve activity.

Keywords: dorsal cochlear nucleus, auditory nerve, synaptic transmission, synaptic plasticity, feedforward inhibition

\section{INTRODUCTION}

In many regions of the mammalian brain, feed-forward inhibition (FFI) represents a complex synaptic arrangement in neuronal networks that results from parallel activation of principal cells and inhibitory interneurons by the same excitatory input (Buzsaki, 1984; Pouille and Scanziani, 2001; Blitz and Regehr, 2005; Gabernet et al., 2005; Mittmann et al., 2005; Cruikshank et al., 2007; Torborg et al., 2010; Ellender et al., 2011; Kuo and Trussell, 2011; Najac et al., 2011; Zhou et al., 2012). Activation of inhibitory interneurons consequently provides inhibition to principal cells to reduce their excitability. The temporal resolution of integration of synaptic inputs depends on the time window within which excitatory inputs can be summated and reach the threshold for firing an action potential in the postsynaptic neuron (Pouille and Scanziani, 2001). The precise timing of excitation and inhibition plays a significant role during high frequency repetitive neuronal activity and has been shown previously to control short-term synaptic plasticity of excitatory and inhibitory inputs (Gabernet et al., 2005; Torborg et al., 2010).
The dorsal cochlear nucleus (DCN) integrates non-auditory and auditory information and plays a role in localization of sound sources and filtering self-generated noise (Shore and Zhou, 2006; Requarth and Sawtell, 2011). Fusiform cells (FCs) are the principal neurons of the DCN that integrate multiple excitatory and inhibitory synaptic inputs onto their apical and basal dendrites (Voigt and Young, 1980, 1990; Blackstad et al., 1984; Oertel and Wu, 1989; Berrebi and Mugnaini, 1991; Zhang and Oertel, 1994). Excitatory inputs contacting apical dendrites of FCs come from granule cell parallel fibers located in the superficial molecular layer. These fibers also innervate cartwheel cells, local glycinergic interneurons that also provide inhibition to FC apical dendrites (Roberts and Trussell, 2010; Kuo and Trussell, 2011). Excitatory inputs onto basal dendrites are conveyed via auditory nerve fibers that carry precisely timed, tonotopically organized acoustic information. Additional excitatory input is formed by the T-stellate cells that send their axons from the ventral cochlear nucleus to the deep layer of the DCN (Oertel and Young, 2004; Oertel et al., 2010). Predominantly glycinergic inhibition terminating 
onto the basal dendrite of FCs is represented by inputs from the tuberculoventral cells (TVCs), also referred to as vertical cells, and D-stellate cells (Zhang and Oertel, 1994), which share the same auditory nerve input with FCs. This complex synaptic arrangement associated with the basal dendrite forms the basis for a feed-forward inhibitory circuit associated with transmission of acoustic information via FCs. Moreover, TVCs form inhibitory synapses onto each other (Kuo et al., 2012). TVCs lie in bands parallel to isofrequency laminae, and their targets, including FCs in the DCN, are innervated by the same auditory nerve fibers (Wickesberg and Oertel, 1988; Voigt and Young, 1990). Moreover, TVCs are sensitive to narrowband stimuli, as only a small number of auditory nerve fibers provide excitation to these interneurons, distinguishing them from D-stellate cells that are sensitive to broadband sounds and are innervated by auditory nerve fibers tuned to a wider frequency range (Voigt and Young, 1990; Winter and Palmer, 1995; Palmer and Winter, 1996). Therefore, inhibition of FCs by TVCs can regulate firing behavior of FCs (Nelken and Young, 1994; Oertel and Young, 2004), although recent evidence indicates the strength of individual connections might be rather weak (Kuo et al., 2012).

To examine the basis for feed-forward inhibitory control and plasticity of auditory processing in the DCN, we determined the synaptic mechanisms that control the balance of excitation and inhibition and affect the output from the nucleus. In this study, we show that short-term synaptic plasticity of auditory nerve-evoked disynaptic inhibition onto FCs exhibits facilitation when activated directly by stimulating inhibitory inputs onto FCs, similar to what has been shown previously using paired recordings from fusiform and TVCs (Kuo et al., 2012). In addition, we show that short-term synaptic plasticity, that is cell type specific in this synaptic circuit, controls FFI received by FCs. We demonstrate that facilitation of TVC-mediated inhibition of FCs shifts to significant depression when driven by the auditory nerve. This shift in synaptic plasticity and excitation-inhibition balance in FCs during repetitive auditory nerve stimulation results from pronounced activitydependent short-term depression of auditory nerve synapses onto TVCs.

\section{MATERIALS AND METHODS COCHLEAR NUCLEUS SLICE PREPARATION}

All experiments were conducted in accordance with animal protocols approved by the NIH Animal Care and Use Committee. P17-P22 C57BL/6 mice of either sex were deeply anesthetized with isoflurane before decapitation and parasagittal brainstem slices containing the cochlear nucleus were cut using a ceramic blade mounted on a vibrating microtome (Leica VT1200S, Leica Microsystems). In order to preserve the complex circuitry and long-distance synaptic connections necessary to study FFI, a midline cut was made, the brainstem was cut into two halves and the medial surface of the right half was glued down to the slicing platform. Then, the first cut was made right above the lateral surface of the cochlear nucleus without touching the surface of the nucleus or the auditory nerve root. A second cut was made to obtain a thick $(380-450 \mu \mathrm{m})$ slice containing most of the cochlear nucleus. Using a thick slice preparation allowed us to preserve the auditory nerve inputs to the DCN which is critical for studying disynaptic inhibition. Dissections were performed in an ice-cold, sucrose-based extracellular solution that contained the following (in $\mathrm{mM}$ ): $75 \mathrm{NaCl}, 26 \mathrm{NaHCO}_{3}$, 75 sucrose, 25 glucose, $2.5 \mathrm{KCl}, 1.25 \mathrm{NaH}_{2} \mathrm{PO}_{4}, 7 \mathrm{MgCl}_{2}, 0.5$ $\mathrm{CaCl}_{2}, 2$ Na-pyruvate, 3 myo-inositol, $0.4 \mathrm{Na}$-ascorbate ( $\mathrm{pH} 7.35$, $\sim 325 \mathrm{mOsm}$ ). Slices were then incubated in the same solution for $20 \mathrm{~min}$ at $34^{\circ} \mathrm{C}$, transferred to saline solution that contained the following (in $\mathrm{mM}$ ): $125 \mathrm{NaCl}, 26 \mathrm{NaHCO}_{3}, 25$ glucose, $2.5 \mathrm{KCl}, 1.25 \mathrm{NaH}_{2} \mathrm{PO}_{4}, 1 \mathrm{MgCl}_{2}, 2 \mathrm{CaCl}_{2}, 2 \mathrm{Na}$-pyruvate, 0.4

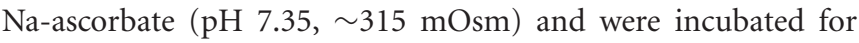
additional $20 \mathrm{~min}$ at $34^{\circ} \mathrm{C}$. All solutions were bubbled with $5 \%$ $\mathrm{O}_{2} / 95 \% \mathrm{CO}_{2}$.

\section{ELECTROPHYSIOLOGY}

Slices were placed in a recording chamber in a way that the intact lateral surface of the nucleus faced the bottom of the chamber and all recordings were made from the medial surface of the DCN. Slices were continuously perfused $(2-3 \mathrm{ml} / \mathrm{min})$ with saline extracellular solution. Fusiform and TVCs were visually identified using a $60 \times 0.9$ NA objective (Olympus) and infrared differential interference contrast. Recording electrodes (2.2-4 M $\Omega$ ) pulled from thick-walled borosilicate glass (Sutter Instruments) were filled with intracellular solution that contained (in mM): $120 \mathrm{CsMeSO}_{4}, 10 \mathrm{HEPES}, 5 \mathrm{NaCl}, 3 \mathrm{MgSO}_{4}$, 2 QX-314, 4 Mg-ATP, 0.4 Na-GTP, 14 Tris-phosphocreatine for voltage-clamp experiments, or (in $\mathrm{mM}$ ): $125 \mathrm{KMeSO}_{4}, 10$ HEPES, $5 \mathrm{NaCl}, 1 \mathrm{MgCl}_{2}, 4 \mathrm{Mg}$-ATP, $0.4 \mathrm{Na}$-GTP, 14 Trisphosphocreatine for current-clamp experiments. To verify the identity of recorded fusiform and tuberculoventral neurons, all intracellular solutions were supplemented with Alexa Fluor 594 hydrazide $(20 \mu \mathrm{M})$. Cell morphology was visualized using a two-photon laser scanning microscope and a Ti:sapphire pulsed laser (Chameleon, Coherent) tuned to $840 \mathrm{~nm}$ for excitation. Data were filtered at 3 or $6 \mathrm{kHz}$ using a Multiclamp $700 \mathrm{~B}$ amplifier (Molecular Devices) and sampled at 10 or $20 \mathrm{kHz}$, respectively. Series resistance (7-18 $\mathrm{M} \Omega$ ) was compensated by $75 \%$ and experiments in which the series resistance increased by $>20 \%$ were excluded from further analysis. To evoke synaptic responses, a tungsten bipolar stimulating electrode with $140 \mu \mathrm{m}$ tip spacing and with tips bent at a $45^{\circ}$ angle (FHC, Bowdoin, ME) was placed in the auditory nerve root (for FFI and direct stimulation of excitatory inputs), or in the deep layer of the DCN (for direct stimulation of inhibitory inputs). Because FCs also receive excitatory granule cell inputs in addition to the auditory nerve inputs, care was taken to directly stimulate auditory nerve fibers in region of the nerve root attached to the ventral region of the cochlear nucleus. The nerve root was readily identified with transmitted light under a $4 \mathrm{x}$ objective, as well as auditory nerve fibers within the root, and could be visually traced beyond the ascending/descending auditory nerve branch bifurcation. However, the placement of the stimulating electrode within the auditory nerve root did not prevent the activation of T-stellate cell excitatory inputs onto FCs in some cases, which could be seen as disynaptic excitation in fusiform cell recordings (for example see Figure $2 \mathrm{~A}$ ). We observed the disynaptic excitation in $\sim 35 \%$ of FCs while recording auditory nerve (AN) evoked EPSCs. These recordings were used for further 
analyses since the later, presumably T-stellate cell-mediated peak did not interfere with the first peak in any way. Moreover, during the FFI trials, the fast kinetics and fast onset of AN evoked inhibitory post-synaptic currents (IPSCs) eliminated the T-stellate cell mediated peak completely. To further ensure and verify that excitation of FCs originated from activation of the auditory nerve fibers, we tested short-term synaptic plasticity of the recorded excitatory responses and verified that excitatory responses were evoked by stimulation of the auditory nerve inputs by the presence of short-term synaptic depression. In contrast. stimulation of parallel fiber synapses evoked synaptic responses that strongly facilitate (Tzounopoulos et al., 2004; Roberts and Trussell, 2010) and can therefore be distinguished from auditory nerve stimulation. Synaptic responses were evoked with $0.2 \mathrm{~ms}$ current pulses $(0-100 \mu \mathrm{A})$ delivered by an isolated stimulus unit (World Precision Instruments). To record FFI consisting of an EPSC-IPSC sequence, FCs were voltage clamped at $-40 \mathrm{mV}$, a holding potential between the reversal potentials for excitatory and inhibitory transmission, and no synaptic blockers were added to the perfusion solution. Direct auditory nerve-evoked EPSCs were recorded at $-60 \mathrm{mV}$ with strychnine $(2 \mu \mathrm{M})$ and picrotoxin $(40 \mu \mathrm{M})$ in the bath. Direct IPSCs were recorded at -40 $\mathrm{mV}$ with 6,7-dinitrodihydroquinoxaline-2,3-dione (DNQX) $(20 \mu \mathrm{M})$ and R-CPP $(5 \mu \mathrm{M})$ in the bath. To analyze timing of FFI, EPSCs were recorded at the chloride reversal potential $\left(\mathrm{E}_{\mathrm{Cl}}=-59\right.$ to $\left.-65 \mathrm{mV}\right)$, IPSCs were recorded at the reversal potential for glutamatergic transmission $\left(E_{\text {glu }}=+5\right.$ to $\left.+12 \mathrm{mV}\right)$, and no synaptic blockers were present in the bath. Recordings were not corrected for the liquid junction potential. Picrotoxin was from Tocris Cookson, DNQX and R-CPP were from Abcam, Alexa Fluor 594 hydrazide was from Invitrogen, all other chemicals were from Sigma. All recordings were performed at $33-35^{\circ} \mathrm{C}$.

\section{DATA ANALYSIS}

All data were acquired and analyzed using custom routines written in Matlab (MathWorks) and IgorPro (WaveMetrics), respectively. Averages are presented as means \pm SEM. To distinguish between facilitating and depressing synapses, the ratio of the 10th stimulus to the 1st stimulus (S10/S1) was calculated. Recordings with $\mathrm{S} 10 / \mathrm{S} 1>1$ were considered facilitating, while those with $\mathrm{S} 10 / \mathrm{S} 1<1$ were considered to be depressing. Latencies were calculated as the time between the beginning of the stimulus artifact and the onset of excitatory/inhibitory synaptic event.

\section{RESULTS}

\section{AUDITORY NERVE ACTIVITY TRIGGERS FEED-FORWARD INHIBITION IN FUSIFORM CELLS}

Basal dendrites of FCs in the DCN receive direct excitatory inputs from the auditory nerve and inhibitory synaptic inputs from TVCs in the deep layer of the DCN (Zhang and Oertel, 1993; Rhode, 1999; Oertel and Young, 2004; Kuo et al., 2012). To further investigate the roles of synaptic excitation and inhibition in auditory processing by FCs, we used parasagittal slices of the cochlear nucleus (see Materials and Methods) that preserve components of the synaptic circuit associated with the fusiform cell basal dendrites (Figure 1).
Whole-cell voltage clamp recordings were made from visually identified FCs. The membrane potential of the fusiform cell was clamped at $-40 \mathrm{mV}$, which is above the reversal potential for inhibitory synaptic currents $\left(\mathrm{E}_{\mathrm{Cl}}, \sim-60 \mathrm{mV}\right)$ and below the reversal for excitatory synaptic currents $\left(\mathrm{E}_{\mathrm{Glu}}, \sim 0 \mathrm{mV}\right)$. Synaptic responses were evoked from a distance of several hundred micrometers from the target postsynaptic neurons. Stimulation of auditory nerve fibers evoked postsynaptic currents in FC (Figure 1A) that consisted of a sequence of inward excitatory (EPSC) and outward inhibitory (IPSC) components (Figure 1B). Subsequent bath application of the glycine receptor antagonist strychnine $(2 \mu \mathrm{M})$ completely blocked the outward component of the synaptic current (Figure 1B, top $n=3$ cells). These results indicate that the inward EPSCs recorded from the FC were evoked directly by stimulation of the auditory nerve fibers.

In separate experiments, application of the AMPA receptor antagonist DNQX $(20 \mu \mathrm{M})$ completely abolished both the inward and outward component. The blockade was partially reversible (Figure 1B, bottom $n=5$ cells). Sensitivity of inhibitory synaptic transmission to a blocker of excitatory transmission demonstrates that the IPSCs were evoked by auditory nerve stimulation rather than by direct activation of inhibitory fibers and were therefore disynaptic in nature. Interneurons providing inhibition to FCs in the deep layer of the DCN have been identified as TVCs (Zhang and Oertel, 1993; Rhode, 1999; Oertel and Young, 2004; Kuo et al., 2012). We conclude that auditory nerve activity drives a feedforward inhibitory circuit in the DCN that includes tuberculoventral cells, DCN interneurons that provide inhibition to FCs in the deep layer of the DCN.

\section{TIMING OF FEED-FORWARD INHIBITION ONTO BASAL DENDRITES OF FUSIFORM CELLS}

Timing of excitatory and inhibitory inputs can have significant consequences for the generation of action potentials in postsynaptic neurons both in the auditory system (Oertel, 1999; Brand et al., 2002), as well as in other brain regions (Buzsaki, 1984; Gil and Amitai, 1996; Borg-Graham et al., 1998). Therefore, having demonstrated the presence of disynaptic inhibition onto fusiform cells evoked by auditory nerve stimulation, we next examined the relative timing of individual components of the feed-forward EPSC-IPSC sequence. We recorded synaptic responses from fusiform cells, and by voltage clamping the cells at different holding potentials we isolated individual components without having to use pharmacological tools. First, we recorded the control FFI sequence at $-40 \mathrm{mV}$ with both inward and outward components present (Figure 2A, top). To isolate the inhibitory component of the sequence, fusiform cells were voltage clamped at the reversal potential for excitatory transmission ( $\mathrm{E}_{\text {glu }},+8.25 \pm 1.5 \mathrm{mV} ; n=4$ cells) and we recorded IPSCs triggered by auditory nerve stimulation. Then, the membrane potential was hyperpolarized to the reversal potential for chloride ions $\left(\mathrm{E}_{\mathrm{Cl}},-60 \pm 0.7 \mathrm{mV} ; n=4\right.$ cells $)$ to isolate EPSCs evoked by auditory nerve stimulation. We analyzed latencies of EPSCs and IPSCs after the stimulus, as well as the interval between the EPSC and IPSC in the sequence. We refer to the beginning of the stimulation artifact as $\mathrm{t} 0$, and to the onsets of EPSC and IPSC as $\mathrm{t} 1$ and $\mathrm{t} 2$, respectively (Figure 2A, bottom). 

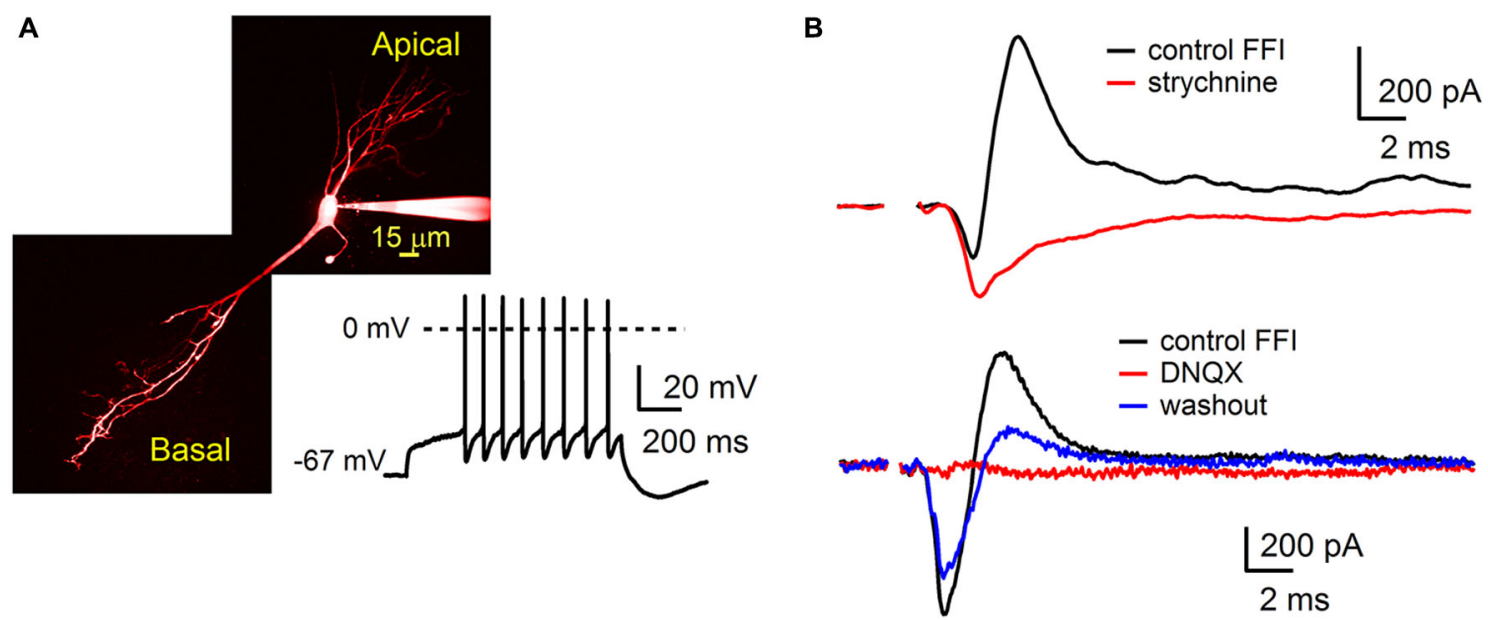

C

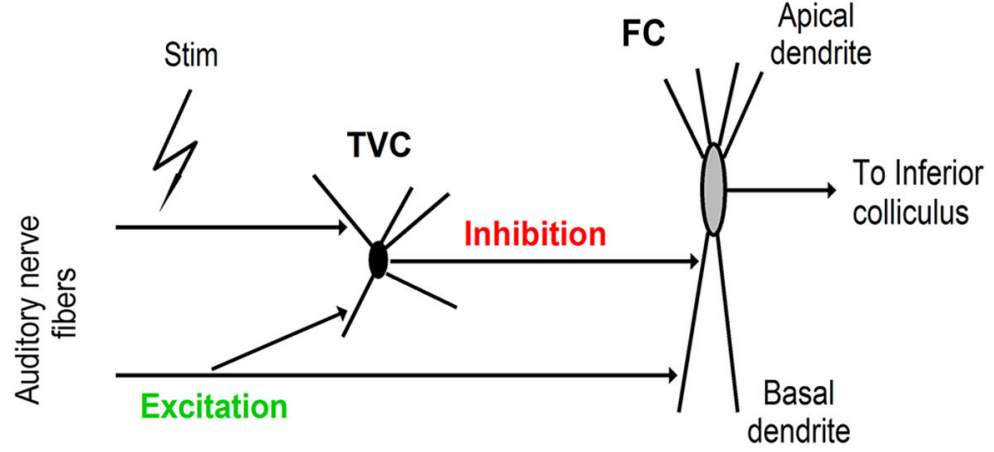

FIGURE 1 | Auditory nerve drives feed-forward inhibition onto fusiform cells in the DCN. (A) A two-photon laser scanning microscopy image of a fusiform cell loaded with Alexa Fluor 594 showing apical and basal dendritic branching. The trace shows a representative example of firing properties of fusiform cells (FCs). Note the delayed spiking pattern (build up) while the cell was held at hyperpolarized membrane potentials. (B) Voltage clamp recordings of feed-forward inhibition from FCs evoked by extracellular stimulation of the auditory nerve. Inhibitory component of the EPSC-IPSC sequence (outward deflection of the black trace) was completely blocked with $2 \mu \mathrm{M}$ strychnine (top traces, $n=3$ cells). Application of AMPA receptor antagonist 6,7-dinitrodihydroquinoxaline2,3-dione (DNQX) (20 $\mu \mathrm{M})$ reversibly blocked both components of the sequence (bottom traces, $n=5$ cells). Stimulation artifacts were removed for clarity. Traces represent averages of 5-10 trials. (C) A schematic of the feed-forward inhibitory circuit driven by the auditory nerve in the dorsal cochlear nucleus. Auditory nerve fibers synapse onto FC, as well as onto tuberculoventral cells (TVC) which further provide inhibition to the FC.
We found that the timing for activation of the feed-forward inhibitory circuit was very precise with latencies of EPSCs, IPCSs and relative EPSC-IPSC sequences of $1.50 \pm 0.16 \mathrm{~ms}$, $2.68 \pm 0.13 \mathrm{~ms}$ and $1.18 \pm 0.09 \mathrm{~ms}$, respectively $(n=4$ cells, Figure 2B).

\section{INNERVATION PATTERNS OF FUSIFORM CELLS AND INTERNEURONS BY AUDITORY NERVE FIBERS}

Auditory nerve fibers innervate both fusiform and TVCs (Wickesberg and Oertel, 1988; Zhang and Oertel, 1994; Fujino and Oertel, 2003). However, the pattern of innervation is not known: disynaptic inhibition in FCs may arise from the activation of the same auditory nerve fibers that form synapses onto both the fusiform and the tuberculoventral cell, or fibers innervating FCs may be different from those innervating tuberculoventral cells. Even though evidence from previous anatomical studies exists that some of the fusiform cell targets of TVCs are innervated by the same auditory nerve fibers as the TVCs themselves (Wickesberg and Oertel, 1988), no physiological evidence exists to support this innervation pattern.

To address this, we recorded FFI in FCs using increasing stimulation intensity to evoke auditory nerve-mediated synaptic responses (Chen and Regehr, 2000; Blitz and Regehr, 2005; Cao and Oertel, 2010; Figure 3). We predicted that if the same set of auditory nerve fibers innervates both the fusiform and the TVCs in the disynaptic circuit, then both the excitatory and inhibitory components would have the same activation threshold. Alternatively, EPSCs and IPSCs could have distinct thresholds, indicative of innervation by different sets of auditory nerve fibers. To distinguish between these possibilities, we used low stimulation intensities $(0-25 \mu \mathrm{A})$ incremented in $1-5 \mu \mathrm{A}$ steps to record both EPSC/IPSC failures and successes. As the stimulation 


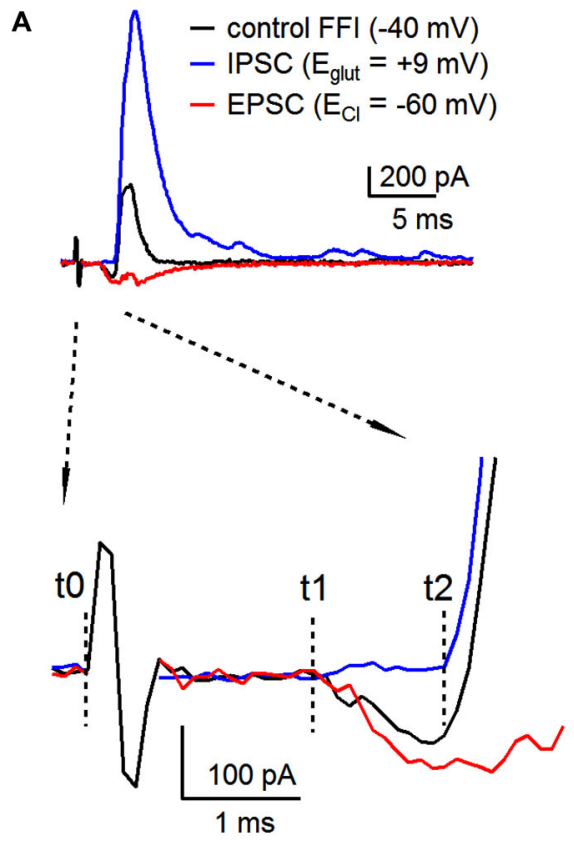

FIGURE 2 | Timing of feed-forward inhibition onto fusiform cells. (A) Latencies of individual components of the EPSC-IPSC sequence (black trace) were examined at respective reversal potentials for excitatory and inhibitory transmission. EPSCs (red trace) were recorded at $\mathrm{E}_{\mathrm{Cl}}(-60 \pm$ $0.7 \mathrm{mV}, n=4$ cells); IPSCs (blue trace) were recorded at $\mathrm{E}_{\text {glut }}(8.25 \pm$ $1.5 \mathrm{mV}, n=4$ cells) (top traces). No synaptic blockers were added to the perfusion solution. Timing of individual components was analyzed using the time difference between the beginning of the stimulating artifact (tO)
B

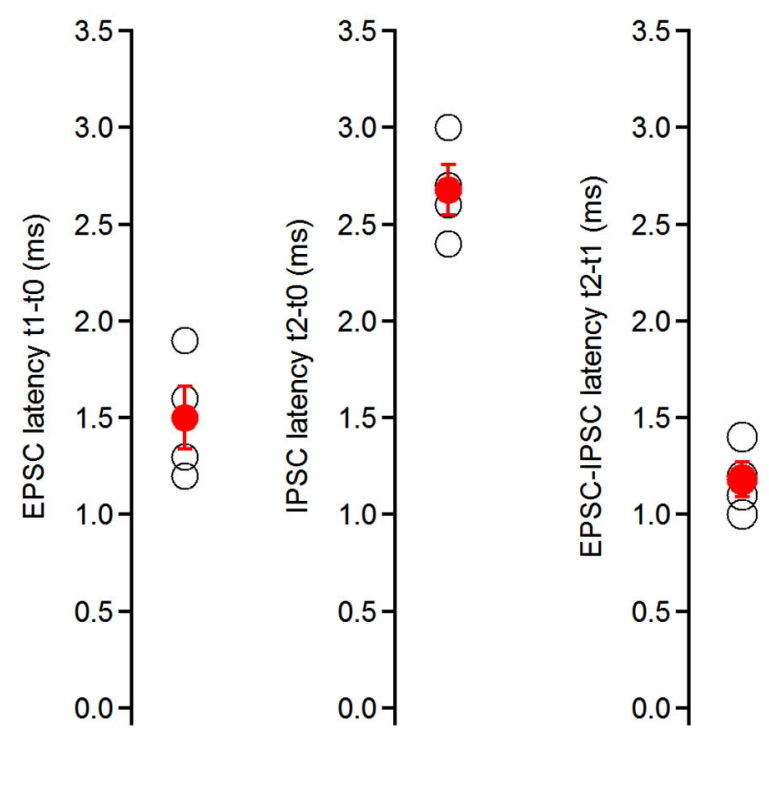

and the onset of synaptic events (t1 for EPSCs, t2 for IPSCs). EPSC-IPSC latency was calculated as $\mathrm{t} 2$ - t1 (bottom traces). Traces represent averages of 5-10 trials. Only stimulation artifact in the control FFI (black) trace is shown, the other two were removed from EPSC and IPSC traces for clarity. (B) Plots of latencies of EPSCs and IPSCs from the stimulation artifact, and timing of EPSC-IPSC sequence. Each black data point represents one neuron; red data points represent averages $\pm \mathrm{SEM} ; n=4$ cells. intensity increased in subsequent trials, successful synaptic events started to appear (Figure 3). We consider the constant stimulation intensity that gave rise to failures and successes to be the minimal stimulation in these experiments.

We found that in a subset of cells, the threshold for evoking both EPSC and IPSC in the disynaptic sequence was different (Figures 3A-E). In this example, the first successful synaptic events recorded were IPSCs without any EPSCs. The latency of these inhibitory responses corresponded to the disynaptic latencies shown in Figure 2, confirming they were not evoked by direct stimulation. As the stimulation intensity increased, the excitatory component appeared as well. This innervation pattern represented $\sim 54 \%$ ( $7 / 13$ FCs). The remaining $\sim 46 \%$ of FCs exhibited an innervation pattern in which thresholds for evoking excitatory and inhibitory components in disynaptic circuit were the same (Figures 3F-J). In this example, both components were recruited at the same level of stimulation intensity. With further increase in the stimulation intensity, the amplitudes of EPSCs remained unchanged, or slightly increased with further stimulation, and the IPSC amplitudes further increased until they reached their maximum value (Figure 3G). We further analyzed the correlation between IPSC/EPSC amplitudes in individual trials to examine whether these are interdependent and possibly activated by the same or different sets of fibers. Figure 3D shows a plot where there is a weak correlation between the IPSC and EPSC amplitudes
$(R=0.20)$, whereas in the case of recordings where both EPSCs and IPSCs have the same activation thresholds, strong correlation $(R=0.87)$ between IPSC and EPSC amplitudes was observed (Figure 3I). Several possible explanations exist for the observed results, although clear and precise conclusions about the innervating pattern by the auditory nerve fibers are difficult to draw. Our results show that distinct auditory nerve fibers may innervate fusiform and TVCs separately, or the same fiber can innervate both cell types. However, since there is no direct evidence for innervation by single auditory nerve fibers, due to insufficient resolution of the stimulation technique, our minimal stimulation trials can also represent activation of multiple weak auditory nerve fibers as with the same activation threshold. Challenging experiments such as simultaneous recordings from fusiform and tuberculoventral cells, while stimulating auditory nerve could eventually provide more insight into the issue.

An interesting and important finding of the presented study is the TVC-mediated amount of inhibition onto FCs. In contrast to previously published results (Kuo et al., 2012) describing unitary TVC to FC connections as weak, we show that increasing intensity of stimulation results in large amount of auditory nerve driven inhibition that is received by FCs. In our FFI experiments, we also analyzed the IPSC amplitudes in order to estimate the minimal and maximal number of TVCs innervating a single FC. Our results show that the minimal amplitude of IPSCs when 
A

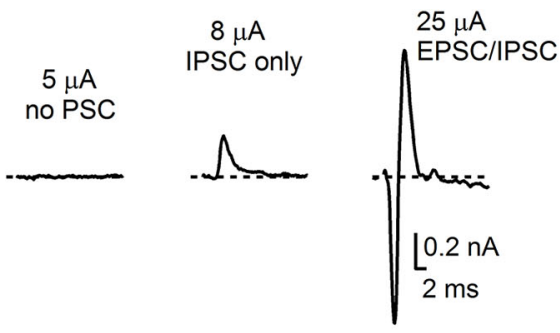

B
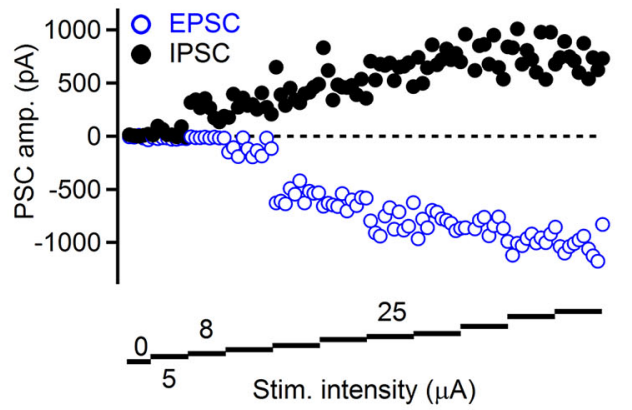

C

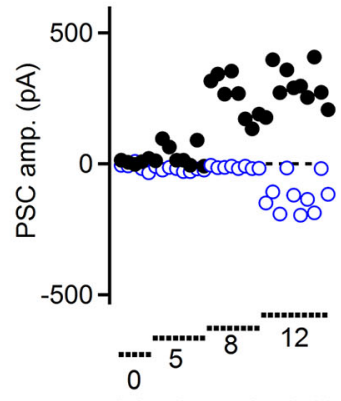

Stim. intensity $(\mu \mathrm{A})$

E

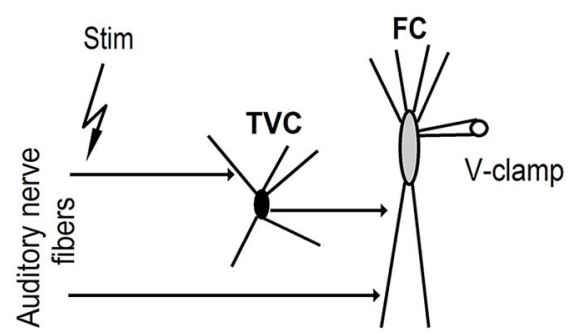

FIGURE 3 | Innervation pattern of the auditory nerve fibers in the dorsal cochlear nucleus. (A) Representative examples of feed-forward inhibition evoked by auditory nerve stimulation and recorded from FCs. At low stimulation intensity, no postsynaptic currents were recorded (left trace). When the stimulation was increased, only an IPSC appeared with a latency that was characteristic for a disynaptic connection (middle trace). With further increase of the stimulation intensity, EPSCs appeared while the amplitude of IPSCs increased (right trace) and amplitudes of both components later saturated. Trials that were evoked with the lowest stimulation intensity evoked both successes and failures of synaptic events that can be seen in the plot shown in (B). (C) Plot of low stimulation evoked EPSC/IPSC amplitudes shown at expanded scale. (D) Plot of IPSC vs. EPSC amplitudes showing low correlation $(R=0.2$ ) between IPSCs and EPSCs. (E) Schematic drawing of the
$\mathbf{F}$

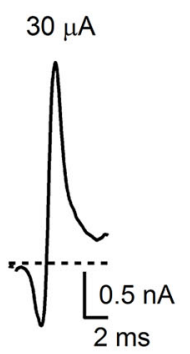

G
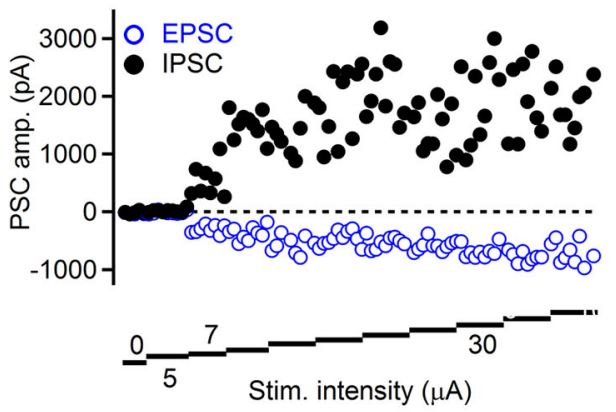

H

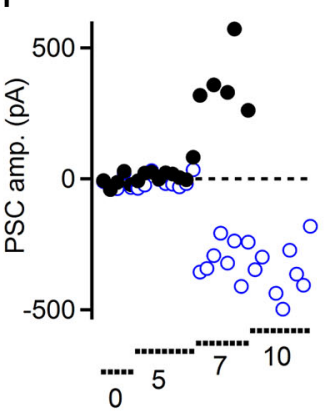

Stim. intensity $(\mu \mathrm{A})$
I

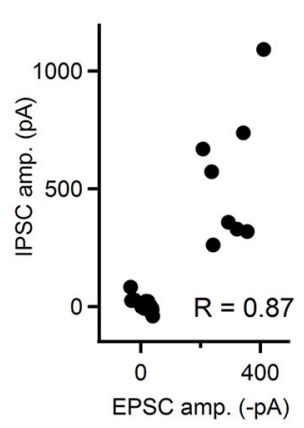

$\mathbf{J}$

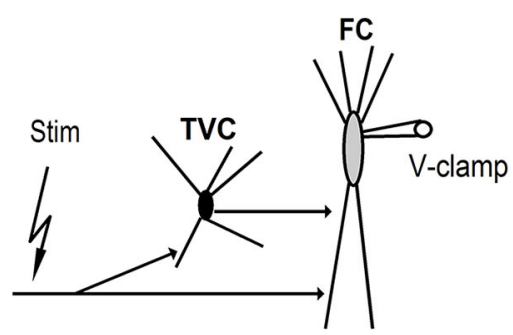

innervation pattern described in A-D. Separate auditory nerve fibers innervate the fusiform (FC) and tuberculoventral (TVC) cells. $~ 54 \%(7 / 13)$ of FCs tested exhibited this type of innervation. (F) Representative examples of FFI and innervation pattern in which the same set of auditory nerve fibers innervates both tuberculoventral and FCs. Following failures in both EPSCs and IPSCs, both components appeared with the same threshold. Stimulation artifacts in $\mathbf{A}$ and $\mathbf{F}$ were removed for clarity and all traces represent averages of 5-10 trials. (G) With increasing stimulation intensity both components increased in their amplitude until both of them reached saturation. (H) Plot of low stimulation evoked EPSC/IPSC amplitudes shown at expanded scale. (I) Plot of IPSC vs. EPSC amplitudes showing high correlation $(R=0.87)$ between IPSCs and EPSCs. (J) A schematic drawing of the innervation pattern shown in $\mathbf{F}-\mathbf{I}$. $\sim 46 \%(6 / 13)$ of FCs tested exhibited this type of innervation. 
we recorded failures and successes during FFI trials was $163 \pm$ $25 \mathrm{pA}$ ( $n=10$ cells), which corresponds to average conductance $4 \mathrm{nS}$ (range 2-7 nS) at $-40 \mathrm{mV}$. The mean saturating amplitude of IPSCs during same FFI trials was $1594 \pm 365$ pA $(n=10$ cells), corresponding to an average conductance of $40 \mathrm{nS}$ (range 9-105 nS) when recorded at $-40 \mathrm{mV}$. Based on the previously reported data on unitary TVC-FC conductance (approximately $2.1 \mathrm{nS}$ at $-60 \mathrm{mV}$ ) (Kuo et al., 2012), our results suggest that the estimated average number of TVCs innervating a single FC is between 2 (activated by a single auditory nerve fiber) and 20 with saturating stimulation intensity. However, the range of unitary conductances that Kuo et al. (2012) report is $0.7-10.3 \mathrm{nS}$, as well as the range of conductances reported in the present study mean that the exact and accurate number of TVCs may vary by several fold. One of the explanations of the discrepancy between our study and Kuo et al. (2012) can be divergence of auditory nerve fibers onto TVCs combined with convergence of TVC inputs to FCs, because auditory nerve fibers can activate multiple TVC inputs to FCs and, moreover, multiple TVCs could innervate a single FC. Also, recording and stimulation conditions in the two studies are markedly different which contributes to the differences in the amount of inhibition observed.

\section{DYNAMICS OF FEED-FORWARD INHIBITORY CIRCUIT DURING REPETITIVE AUDITORY NERVE ACTIVITY}

Excitatory synapses formed by the auditory nerve onto various postsynaptic targets in all three subdivisions of the cochlear nucleus exhibit short-term synaptic plasticity with varying amounts of synaptic depression related to their specific postsynaptic target, including FCs in the DCN (Wu and Oertel, 1987; Cao et al., 2008; Yang and Xu-Friedman, 2008; Cao and Oertel, 2010; Chanda and Xu-Friedman, 2010; Kuo et al., 2012). Relatively less is known about the short-term synaptic plasticity of inhibitory inputs that contact basal dendrites of FCs (Kuo et al., 2012). Also, little is known about the temporal dynamics of FFI with both excitation and inhibition intact.

Therefore, to ask how repetitive activity of the auditory nerve affects the FFI onto the FCs, we first recorded mixed excitatory and inhibitory responses in response to stimulus trains delivered to the auditory nerve. FCs were voltage clamped at $-40 \mathrm{mV}$ and FFI was evoked by repetitive stimulation of the auditory nerve (10 stimuli) at 20,50 and $100 \mathrm{~Hz}$. We found that the feed-forward inhibitory circuit associated with basal dendrites of FCs undergoes short-term synaptic plasticity at all frequencies tested (Figure 4). However, plasticity of excitation and inhibition differed. After 10 stimuli delivered to the auditory nerve, the amplitude of the last EPSC in the train was not significantly different from the first EPSC at the frequencies tested ( $94 \pm 9 \%$, $115 \pm 11 \%$ and $104 \pm 4 \%$, at 20,50 , and $100 \mathrm{~Hz}$ respectively, Figures $4 \mathrm{~A}-\mathrm{D}, n=6$ cells). In contrast to the excitation, the inhibitory component of FFI exhibited significant depression at all frequencies tested (S10/S1 of $48 \pm 9 \%, 57 \pm 10 \%$, and $59 \pm$ $11 \%$ at 20, 50 and $100 \mathrm{~Hz}$ stimulation, respectively, Figure 4E). In sum, these results show that repetitive auditory nerve stimulation generates mixed excitatory-inhibitory responses. The excitatory component exhibits little short-term plasticity when activated at $20-100 \mathrm{~Hz}$. In contrast the inhibitory component exhibits moderate depression of $40-50 \%$.

Recently it has been shown that IPSCs evoked in FCs by stimulation of TVCs exhibit mild facilitation when activated at $100 \mathrm{~Hz}$ in paired recordings (Kuo et al., 2012), which is in contrast with our observation of IPSC depression. One factor that can influence the amplitudes of EPSCs and IPSCs in FCs during the biphasic response to auditory nerve stimulation is temporal overlap of the synaptic conductances. Although IPSCs are disynaptic and therefore have a longer latency, FCs exhibit relatively slow EPSC kinetics compared to other auditory nerve targets (Gardner et al., 1999) and therefore the inward peak of the biphasic response can be truncated by onset of the fast IPSC. An additional factor that can influence IPSC amplitudes during FFI is plasticity at the auditory nerve to tuberculoventral cell synapse. Either of these factors could explain differences in short-term plasticity of IPSCs when evoked by direct activation of inhibitory axons compared to those evoked by feed-forward activation of interneurons by auditory nerve fibers. We therefore performed experiments to test these possibilities.

In the first set of experiments we examined short-term plasticity of pharmacologically-isolated excitatory and inhibitory inputs onto FCs. By blocking GABA and glycine receptors (with picrotoxin and strychnine, respectively) we recorded isolated auditory nerve EPSCs evoked at 20-100 Hz. Under conditions where FFI is blocked (Figure 5A), auditory nerve-evoked EPSCs undergo slight depression ( $\mathrm{S} 10 / \mathrm{S} 1$ of $83 \pm 6 \%, 93 \pm 4 \%$ and $86 \pm 11 \%$ at 20,50 and $100 \mathrm{~Hz}$, respectively, Figures $5 \mathbf{A}, \mathbf{B}, n=5$ cells).

Next, we recorded IPSCs from FCs in the presence of DNQX and R-CPP, blockers of excitatory transmission, to investigate whether the amount of IPSC synaptic depression would be the same as during the FFI trials. FCs were voltage clamped at $-40 \mathrm{mV}$ and IPSCs were evoked by direct stimulation of inhibitory inputs in the deep layer of the DCN (Figure 5C). Surprisingly, IPSC trains exhibited slight synaptic depression at $20 \mathrm{~Hz}$ (S10/S1 was $82 \pm 1 \%$ ), and slight facilitation at 50 and $100 \mathrm{~Hz}$, respectively (S10/S1 at $50 \mathrm{~Hz}$ was $103 \pm 5 \%, \mathrm{~S} 10 / \mathrm{S} 1$ at $100 \mathrm{~Hz}$ was $119 \pm 13 \% ; n=6$ cells, Figure 5D). These results are consistent with previously reported data from paired recordings between tuberculoventral and FCs (Kuo et al., 2012). However, the comparatively moderate short-term plasticity of directly evoked and pharmacologically isolated IPSCs seems unlikely to explain the pronounced short-term depression of inhibition during FFI when excitation and inhibition are intact.

Therefore, we next investigated whether short-term plasticity at the auditory nerve to tuberculoventral cell synapse accounts for the strong IPSC depression during FFI. For this purpose, we recorded auditory nerve-evoked EPSCs from TVCs visually identified in the slice (Figure 6A). One characteristic of TVCs is that they exhibit fast EPSCs with sub-millisecond decay kinetics (Gardner et al., 1999; Kuo et al., 2012). In our experiments, we confirmed this (Figure 6B) and used the rapidly decaying spontaneous synaptic events as a criteria for distinguishing TVCs from other cell types in the deep layer of the DCN (Gardner et al., 1999). Another distinguishing characteristic is that TVCs are mostly electrically silent (Shofner and Young, 1985; Spirou et al., 1999), and in slices rarely spike spontaneously (Kuo et al., 

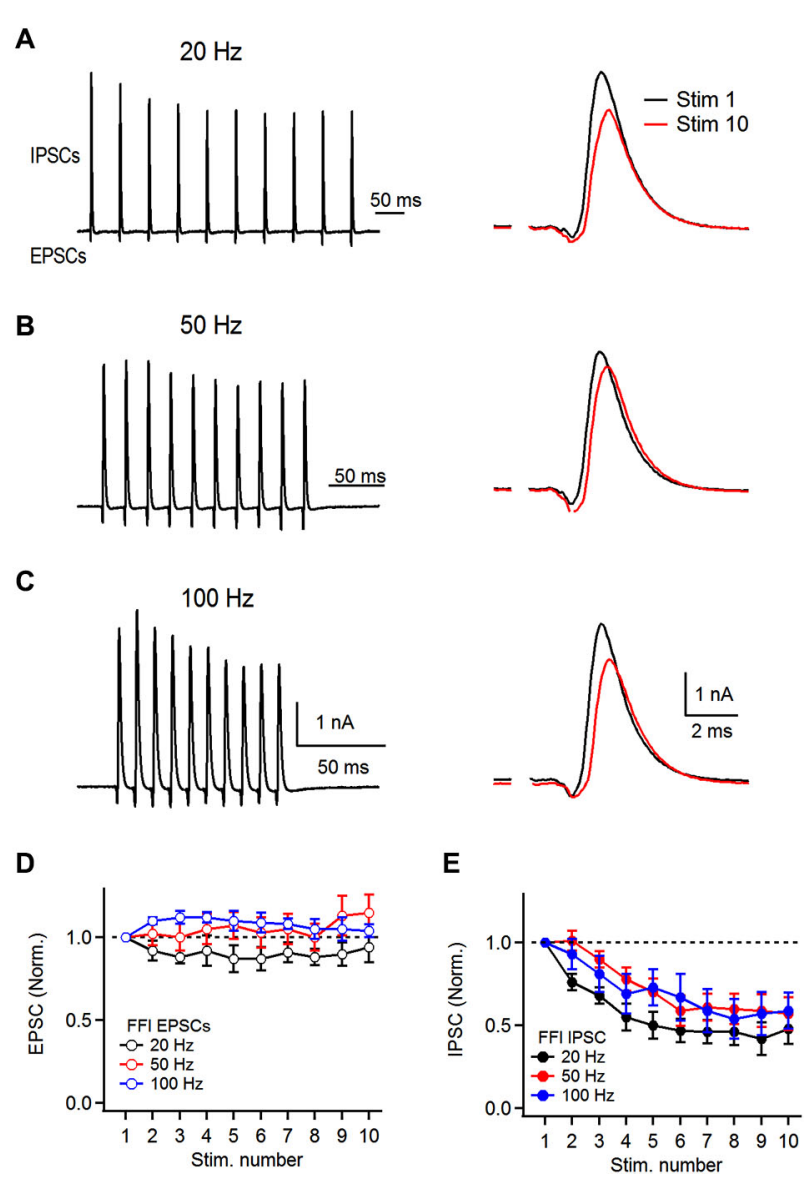

FIGURE 4 | Dynamics of feed-forward inhibitory circuit during repetitive auditory nerve activity. (A) Representative recordings of feed-forward inhibition. 10 stimuli were delivered to the auditory nerve at $20 \mathrm{~Hz}$ and short-term plasticity of both the excitatory and the inhibitory components was analyzed. Stimulation artifacts were removed for clarity from all traces shown. Response to the first (Stim 1) and 10th (Stim 10) are superimposed on

the right. (B,C) Recordings of feed-forward inhibition in FCs at 50 and $100 \mathrm{~Hz}$. (D) Plot of EPSC short-term plasticity in the EPSC-IPSC sequence at 20, 50 and $100 \mathrm{~Hz}$. Amplitudes were normalized to the first EPSC in the train. (E) Plot of IPSC short-term plasticity during FFI trials at 20, 50 and $100 \mathrm{~Hz}$ showing pronounced depression. IPSCs were normalized to the first PSC in the train (B and $\mathbf{C}, n=6$ cells).

2012), which we confirmed by recording in cell-attached mode before breaking into the whole-cell configuration (data not shown). Finally, we confirmed the cell identity by inspecting their morphology using fluorescent dye in the recording pipette (Figure 6A). EPSCs recorded from TVCs were evoked by extracellular stimulation of the auditory nerve (Figure 6C), similar to EPSCs recorded from the FCs. Repetitive stimulation of the auditory nerve with 10 stimuli evoked a train of EPSCs that exhibited pronounced short-term synaptic depression (Figure 6D). At all frequencies tested (20,50 and $100 \mathrm{~Hz}$ ), EPSCs significantly depressed with S10/S1 of $48 \pm 1 \%, 41 \pm 3 \%$ and $35 \pm 4 \%$ at 20,50 and $100 \mathrm{~Hz}$, respectively (Figure $6 \mathrm{E}, n=6$ cells). These values match very closely with the amount of depression of IPSCs evoked during FFI recorded from the FCs (see Figure 4). Therefore, these results, together with our previous findings strongly indicate that short-term depression at the synapse between the auditory nerve and tuberculoventral cell accounts for the activity dependent change in excitation-inhibition balance in a synapse specific manner. It also accounts for the observed shift in short-term synaptic plasticity of fusiform cell deep-layer inhibition, from facilitation when IPSCs are directly stimulated, to strong depression when FFI is intact.

\section{DISCUSSION}

In the current study, we investigated the properties and mechanisms of FFI in the DCN driven by the auditory nerve. We used patch clamp recordings from fusiform and TVCs to provide evidence that synapse specific and activity dependent synaptic plasticity regulates the balance of excitation and inhibition in a feed-forward inhibitory synaptic circuit associated with basal dendrites of FCs in the DCN.

Our results show that auditory nerve fibers activate both FCs and TVCs that represent the DCN principal neurons and local interneurons, respectively. TVCs further provide strong FFI to FCs. The strong inhibition of FCs that we observe differs from what has recently been shown by Kuo et al. (2012), who demonstrate that connections between TVCs and FCs are rather weak. One explanation that can account for this discrepancy 
A Isolated EPSCs
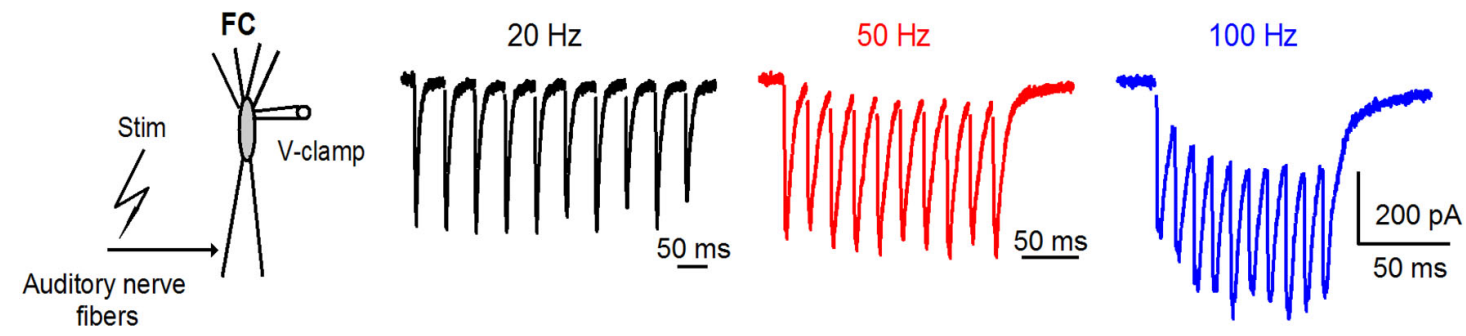

B
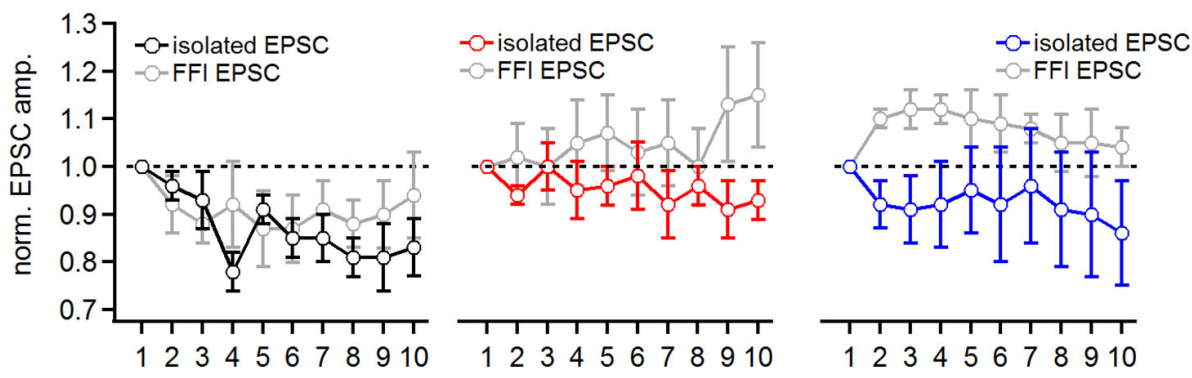

C
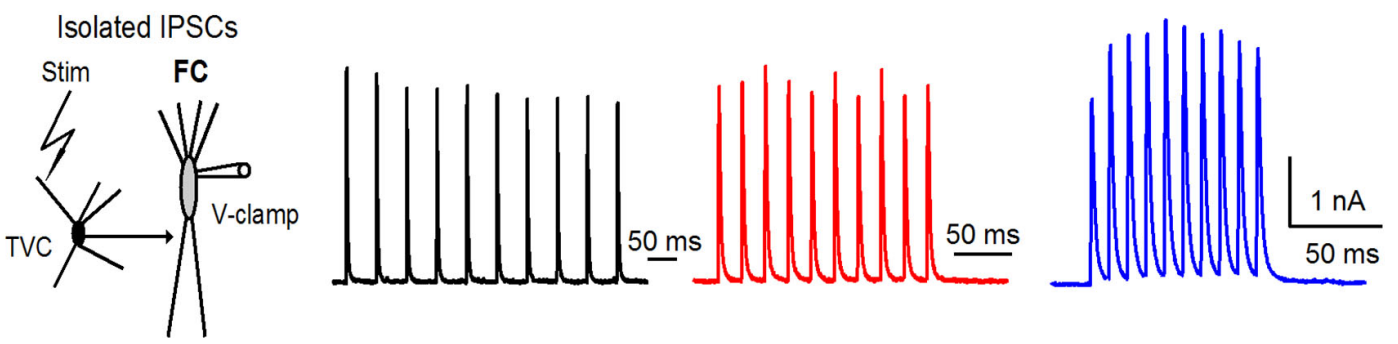

D
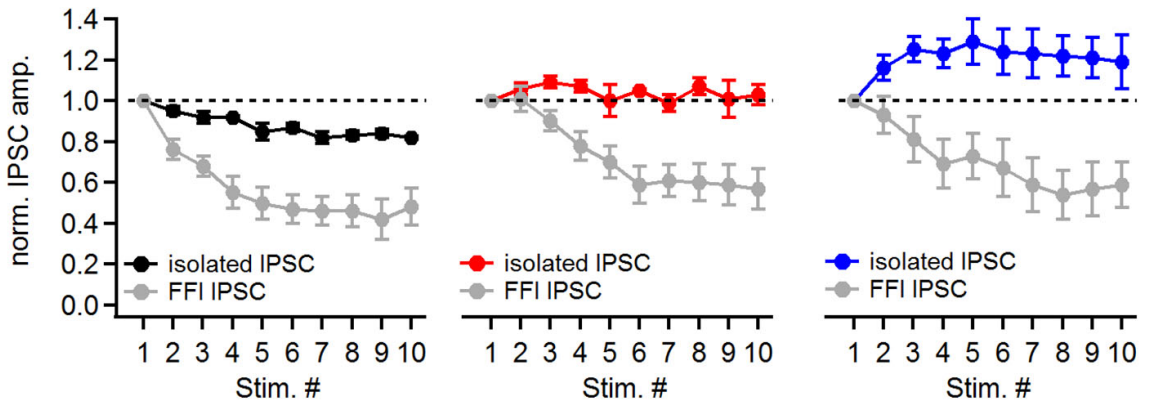

FIGURE 5 | Short-term plasticity of directly stimulated excitatory and inhibitory inputs onto basal dendrites of fusiform cells. (A)

Representative examples of EPSCs recorded from a fusiform cell evoked by 20, 50 and $100 \mathrm{~Hz}$ auditory nerve stimulation. Schematic in the left shows the experimental protocol. Recordings were performed with $2 \mu \mathrm{M}$ strychnine and $40 \mu \mathrm{M}$ picrotoxin in perfusion solution. (B) Plots of EPSC amplitudes at corresponding stimulation frequencies of the auditory nerve. EPSCs in the train were normalized to the first EPSC in the train. For comparison, gray data points in all three graphs represent data of EPSC short-term plasticity evoked during feed-forward inhibition trials shown in Figure 4 ( $n=5$ cells). (C) Representative examples of IPSCs recorded from a fusiform cell evoked by direct stimulation of inhibitory inputs in the deep layer of the DCN at 20,50 and $100 \mathrm{~Hz}$. Schematic drawing in the left shows the experimental protocol. All recordings were done in $20 \mu \mathrm{M}$ DNXQ and $5 \mu \mathrm{M}$ R-CPP to block excitatory transmission. (D) Plots of IPSC amplitudes in the train normalized to the first IPSC at corresponding frequencies of stimulation of inhibitory inputs. Gray data of IPSC short-term plasticity recorded during feed-forward inhibition trials and shown in Figure $\mathbf{4}$ are included for comparison. Differences in short-term plasticity of directly stimulated IPSCs and those evoked during FFI were statistically significant $(P<0.001, n=6$ cells). All stimulation artifacts in $\mathbf{A}$ and $\mathbf{C}$ were removed for clarity. Traces represent averages of 5-10 trials. is that the stimulation paradigms between the two studies are different. Paired recordings that Kuo et al. (2012) used in their study represent unitary connections with only a small number of synapses being activated. In case of our experiments, bulk stimulation of the auditory nerve activates multiple auditory nerve fibers that could lead to activation of multiple TVC inputs 
A

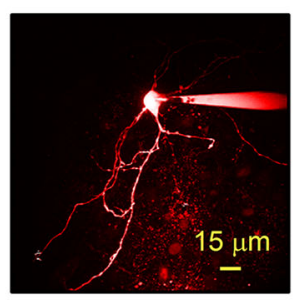

C

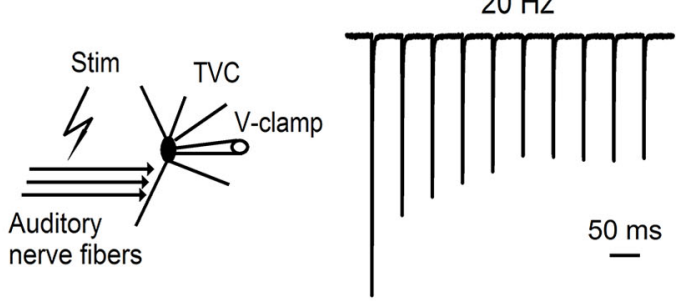

E

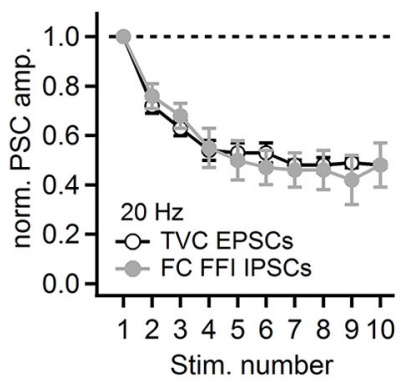

FIGURE 6 | Synaptic plasticity at the auditory nerve-tuberculoventral cell synapse regulates feed-forward inhibition onto fusiform cells. (A) A two-photon laser scanning microscopy image of a tuberculoventral cell loaded with Alexa Fluor 594. (B) Electrophysiological properties of tuberculoventral cells in DCN slices. Top traces show tonic firing upon prolonged

depolarization, high input resistance examined with hyperpolarizing current injection that resulted in rebound firing when returned back to resting membrane potential $(-66 \mathrm{mV})$. Bottom trace shows a representative example of a spontaneous EPSC (sEPSC). Single exponential fit of the rapid decay kinetics is shown in red. (C) Experimental protocol for recording auditory nerve evoked EPSCs from tuberculoventral cells. (D) Short-term plasticity of
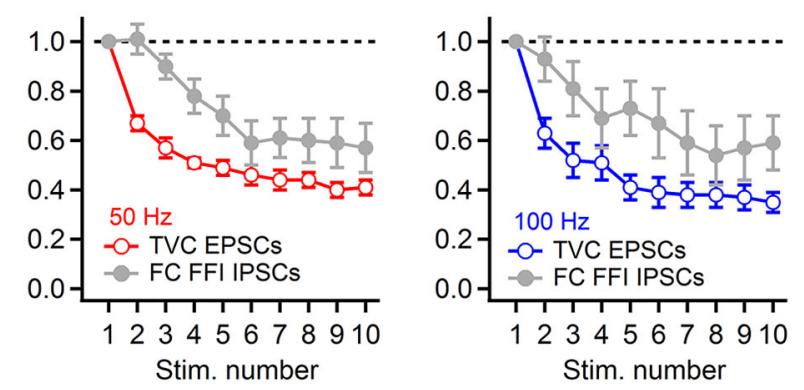

EPSCs recorded from a tuberculoventral cell during repetitive auditory nerve stimulation at 20,50 and $100 \mathrm{~Hz}$. All recordings were performed with $2 \mu \mathrm{M}$ strychnine and $40 \mu \mathrm{M}$ picrotoxin in the perfusion solution. Note the pronounced depression that is comparable to the amount of depression of the inhibitory component of FFI sequence recorded from FCs. Stimulation artifacts were removed for clarity. Traces represent averages of 5-10 trials. (E) Plots of EPSC amplitudes at corresponding stimulation frequencies of the auditory nerve. Gray data of IPSC short-term plasticity recorded from FCs during feed-forward inhibition trials and shown in Figure $\mathbf{4}$ are included for comparison. EPSCs in the train were normalized to the first EPSC in the train ( $n=6$ cells $)$. to FCs. In addition, multiple TVCs could innervate a single FC which would further increase the amount of inhibition recorded from a single FC. A more complete understanding of the circuit mechanisms that control fusiform cell responses to sound will also require understanding of the effects of inhibitory contacts among TVCs themselves (Kuo et al., 2012).

The activation and timing of the disynaptic inhibition that we recorded was fast and very precisely timed, occurring within approximately $1 \mathrm{~ms}$ after auditory nerve activation. The narrow time window for summation of inputs has been shown to play a significant role in reaching action potential threshold in postsynaptic neurons (Pouille and Scanziani, 2001), and it is likely to be important in regulating the output of the DCN. Fast and consistently narrow jitter of FFI timing in our experiments provides further evidence for a disynaptic connection. The delay that we describe here is comparable with timing of FFI in the visual system (Blitz and Regehr, 2005), cerebellum (Mittmann et al., 2005) or cortex (Gabernet et al., 2005), but was shorter than in case of FFI described previously in hippocampus (Pouille and Scanziani, 2001; Torborg et al., 2010). Different needs for speed of synaptic transmission and input integration in various brain regions may account for these discrepancies. One of the mechanisms underlying the precision and accurate timing of FFI in the local DCN circuit that we studied may be the kinetics of EPSCs evoked in TVCs by stimulation of auditory nerve fibers. Previous studies (Gardner et al., 1999, 2001), and our data (Figures 6B,D) demonstrate that TVC EPSCs exhibit extremely fast kinetics. The rapid decay kinetics is hypothesized 
to be predominantly due to expression of fast AMPA receptors containing GluR4 subunits in cells receiving exclusively auditory nerve excitatory inputs (Gardner et al., 1999, 2001).

By using low-intensity stimulation of the auditory nerve we further observe that some auditory nerve fibers evoke a biphasic response in FCs that consists of a monosynaptic EPSC and a disynaptic IPSC. In other cases, EPSCs exhibited a higher threshold for activation and only IPSCs were observed. With increasing stimulation intensity, and thus recruiting more auditory nerve fibers, we observed that excitatory and/or inhibitory components of the FFI began to be recruited gradually and contributed to the overall complex responses recorded from FCs. Similar observations have been described in the visual system (Blitz and Regehr, 2005); however, unlike the mentioned study, we were not always able to distinguish activation of a single auditory nerve fiber from activation of a few weaker fibers in our experiments. Therefore, it is difficult to draw clear conclusions defining the precise innervation pattern of fusiform and TVCs by auditory nerve fibers. Using a challenging approach such as simultaneous recordings from both fusiform and TVCs while stimulating the auditory nerve could help resolve this issue.

Data from in vivo experiments show that FCs can be divided into two groups, intensity-selective and intensity-nonselective, based on their responses to sound of various intensities (Zhou et al., 2012). Intensity-selective neurons have a non-monotonic rate-level function and thus respond most strongly to sounds of a specific intensity, whereas intensity non-selective neurons have a monotonic rate-level function. Although the circuit mechanisms for these distinct response types are not known, an intriguing possibility is that differential patterns of FFI by TVCs could play a role. TVCs in DCN are thought to represent type II neurons (Davis and Voigt, 1997; Rhode, 1999) and are important for intensity selectivity of FCs because of their ability to suppress or even eliminate FC firing. Therefore, the innervation patterns of FCs and TVCs can play a crucial role in the output of the DCN since low sound intensities can recruit excitatory inputs onto FCs in the absence of inhibition. Further increases in sound intensity strengthens both excitatory and inhibitory components (Zhou et al., 2012). Our results demonstrate strongly increasing amplitude of inhibition as progressively more auditory nerve fibers are activated, a situation analogous to progressive recruitment of auditory nerve fibers by increasing sound intensity.

An important question related to synaptic input integration and information processing is how repetitive activity regulates the output of a synaptic circuit, especially when both excitatory and inhibitory components are involved. Excitatory synapses between the auditory nerve and its targets have been shown to exhibit various amounts of short-term synaptic depression depending on the type of postsynaptic neuron (Cao and Oertel, 2010; Kuo et al., 2012). Consistent with recent work (Kuo et al., 2012), we observe minimal depression at the auditory nerve-FC synapse and pronounced depression at the synapse between the auditory nerve and TVCs, under conditions where excitation and inhibition, respectively, were pharmacologically isolated. This indicates target-specific specializations of short-term synaptic plasticity, a phenomenon that has also been reported in other brain areas, but is not well understood (Blackman et al., 2013). However, examination of short-term plasticity of EPSCs and IPSCs recorded from FCs during FFI trials provided evidence that shortterm plasticity of synaptic currents under conditions when both components are present differs from that recorded when either of the two components is isolated. Such differences may arise from temporal overlap of synaptic conductances during repetitive stimulation. In the case of DCN FCs, the combination of relatively slow EPSC kinetics (Gardner et al., 1999) and fast IPSC kinetics (Xie and Manis, 2013) results in greater summation of excitatory responses during repetitive synaptic activity and IPSC amplitudes are consequently reduced by the tonic inward current. A second factor is synaptic depression at the auditory nervetuberculoventral cell synapse (Kuo et al., 2012, our Figure 6). In DCN FCs, synaptic depression at the feed-forward synapse onto the inhibitory interneuron is of greater magnitude than the degree of summation of either excitatory or inhibitory responses during repetitive activation of the feed-forward circuit. In conclusion, our study demonstrates how FFI can regulate the balance of excitation and inhibition in FCs in a dynamic manner during repetitive auditory nerve activity, findings that may be relevant for our understanding of the role of FFI in other brain regions as well.

\section{ACKNOWLEDGMENTS}

This work was supported by the National Institute on Deafness and Other Communication Disorders Intramural Research Program.

\section{REFERENCES}

Berrebi, A. S., and Mugnaini, E. (1991). Distribution and targets of the cartwheel cell axon in the dorsal cochlear nucleus of the guinea pig. Anat. Embryol. (Berl) 183, 427-454. doi: 10.1007/bf00186433

Blackman, A. V., Abrahamsson, T., Costa, R. P., Lalanne, T., and Sjöström, P. J. (2013). Target-cell-specific short-term plasticity in local circuits. Front. Synaptic Neurosci. 5:11. doi: 10.3389/fnsyn.2013.00011

Blackstad, T. W., Osen, K. K., and Mugnaini, E. (1984). Pyramidal neurones of the dorsal cochlear nucleus: a Golgi and computer reconstruction study in cat. Neuroscience 13, 827-854. doi: 10.1016/0306-4522(84)90099-x

Blitz, D. M., and Regehr, W. G. (2005). Timing and specificity of feed-forward inhibition within the LGN. Neuron 45, 917-928. doi: 10.1016/j.neuron.2005. 01.033

Borg-Graham, L. J., Monier, C., and Frégnac, Y. (1998). Visual input evokes transient and strong shunting inhibition in visual cortical neurons. Nature 393, 369-373. doi: 10.1038/30735

Brand, A., Behrend, O., Marquardt, T., McAlpine, D., and Grothe, B. (2002). Precise inhibition is essential for microsecond interaural time difference coding. Nature 417, 543-547. doi: 10.1038/417543a

Buzsaki, G. (1984). Feed-forward inhibition in the hippocampal formation. Prog. Neurobiol. 22, 131-153. doi: 10.1016/0301-0082(84)90023-6

Cao, X. J., McGinley, M. J., and Oertel, D. (2008). Connections and synaptic function in the posteroventral cochlear nucleus of deaf jerker mice. J. Comp. Neurol. 510, 297-308. doi: 10.1002/cne.21788

Cao, X. J., and Oertel, D. (2010). Auditory nerve fibers excite targets through synapses that vary in convergence, strength and short-term plasticity. J. Neurophysiol. 104, 2308-2320. doi: 10.1152/jn.00451.2010

Chanda, S., and Xu-Friedman, M. A. (2010). A low-affinity antagonist reveals saturation and desensitization in mature synapses in the auditory brain stem. J. Neurophysiol. 103, 1915-1926. doi: 10.1152/jn.00751.2009

Chen, C., and Regehr, W. G. (2000). Developmental remodeling of the retinogeniculate synapse. Neuron 28, 955-966. doi: 10.1016/s0896-6273(00)00166-5

Cruikshank, S. J., Lewis, T. J., and Connors, B. W. (2007). Synaptic basis for intense thalamocortical activation of feedforward inhibitory cells in neocortex. Nat. Neurosci. 10, 462-468. doi: 10.1038/nn1861 
Davis, K. A., and Voigt, H. F. (1997). Evidence of stimulus-dependent correlated activity in the dorsal cochlear nucleus of decerebrate gerbils. J. Neurophysiol. 78, 229-247.

Ellender, T. J., Huerta-Ocampo, I., Deisseroth, K., Capogna, M., and Bolam, J. P. (2011). Differential modulation of excitatory and inhibitory striatal synaptic transmission by histamine. J. Neurosci. 31, 15340-15351. doi: 10. 1523/JNEUROSCI.3144-11.2011

Fujino, K., and Oertel, D. (2003). Bidirectional synaptic plasticity in the cerebellum-like mammalian dorsal cochlear nucleus. Proc. Natl. Acad. Sci. U S A 100, 265-270. doi: 10.1073/pnas.0135345100

Gabernet, L., Jadhav, S. P., Feldman, D. E., Carandini, M., and Scanziani, M. (2005). Somatosensory integration controlled by dynamic thalamocortical feed-forward inhibition. Neuron 48, 315-327. doi: 10.1016/j.neuron.2005. 09.022

Gardner, S. M., Trussell, L. O., and Oertel, D. (1999). Time course and permeation of synaptic AMPA receptors in cochlear nuclear neurons correlate with input. J. Neurosci. 19, 8721-8729.

Gardner, S. M., Trussell, L. O., and Oertel, D. (2001). Correlation of AMPA receptor subunit composition with synaptic input in the mammalian cochlear nuclei. J. Neurosci. 21, 7428-7437.

Gil, Z., and Amitai, Y. (1996). Properties of convergent thalamocortical and intracortical synaptic potentials in single neurons of neocortex. J. Neurosci. 16, 6567-6578.

Kuo, S. P., Lu, H. W., and Trussell, L. O. (2012). Intrinsic and synaptic properties of vertical cells of the mouse dorsal cochlear nucleus. J. Neurophysiol. 108, 11861198. doi: 10.1152/jn.00778.2011

Kuo, S. P., and Trussell, L. O. (2011). Spontaneous spiking and synaptic depression underlie noradrenergic control of feed-forward inhibition. Neuron 71, 306-318. doi: 10.1016/j.neuron.2011.05.039

Mittmann, W., Koch, U., and Häusser, M. (2005). Feed-forward inhibition shapes the spike output of cerebellar Purkinje cells. J. Physiol. 563, 369-378. doi: 10. 1113/jphysiol.2004.075028

Najac, M., De Saint Jan, D., Reguero, L., Grandes, P., and Charpak, S. (2011). Monosynaptic and polysynaptic feed-forward inputs to mitral cells from olfactory sensory neurons. J. Neurosci. 31, 8722-8729. doi: 10.1523/jneurosci.052711.2011

Nelken, I., and Young, E. D. (1994). Two separate inhibitory mechanisms shape the responses of dorsal cochlear nucleus type IV units to narrowband and wideband stimuli. J. Neurophysiol. 71, 2442-2462.

Oertel, D. (1999). The role of timing in the brain stem auditory nuclei of vertebrates. Annu. Rev. Physiol. 61, 497-519. doi: 10.1146/annurev.physiol.61.1.497

Oertel, D., Wright, S., Cao, X. J., Ferragamo, M., and Bal, R. (2010). The multiple functions of T stellate/multipolar/chopper cells in the ventral cochlear nucleus. Hear. Res. 276, 61-69. doi: 10.1016/j.heares.2010.10.018

Oertel, D., and Wu, S. H. (1989). Morphology and physiology of cells in slice preparations of the dorsal cochlear nucleus of mice. J. Comp. Neurol. 283, 228 247. doi: 10.1002/cne.902830206

Oertel, D., and Young, E. D. (2004). What's a cerebellar circuit doing in the auditory system? Trends Neurosci. 27, 104-110. doi: 10.1016/j.tins.2003.12.001

Palmer, A. R., and Winter, I. M. (1996). The temporal window of two-tone facilitation in onset units of the ventral cochlear nucleus. Audiol. Neurootol. 1, 12-30. doi: 10.1159/000259199

Pouille, F., and Scanziani, M. (2001). Enforcement of temporal fidelity in pyramidal cells by somatic feed-forward inhibition. Science 293, 1159-1163. doi: 10 . $1126 /$ science. 1060342

Requarth, T., and Sawtell, N. B. (2011). Neural mechanisms for filtering selfgenerated sensory signals in cerebellum-like circuits. Curr. Opin. Neurobiol. 21, 602-608. doi: 10.1016/j.conb.2011.05.031

Rhode, W. S. (1999). Vertical cell responses to sound in cat dorsal cochlear nucleus. J. Neurophysiol. 82, 1019-1032.
Roberts, M. T., and Trussell, L. O. (2010). Molecular layer inhibitory interneurons provide feedforward and lateral inhibition in the dorsal cochlear nucleus. J. Neurophysiol. 104, 2462-2473. doi: 10.1152/jn.00312.2010

Shofner, W. P., and Young, E. D. (1985). Excitatory/inhibitory response types in the cochlear nucleus: relationships to discharge patterns and responses to electrical stimulation of the auditory nerve. J. Neurophysiol. 54, 917-939.

Shore, S. E., and Zhou, J. (2006). Somatosensory influence on the cochlear nucleus and beyond. Hear. Res. 216-217, 90-99. doi: 10.1016/j.heares.2006.01.006

Spirou, G. A., Davis, K. A., Nelken, I., and Young, E. D. (1999). Spectral integration by type II interneurons in dorsal cochlear nucleus. J. Neurophysiol. 82, 648-663.

Torborg, C. L., Nakashiba, T., Tonegawa, S., and McBain, C. J. (2010). Control of CA3 output by feedforward inhibition despite developmental changes in the excitation-inhibition balance. J. Neurosci. 30, 15628-15637. doi: 10. 1523/jneurosci.3099-10.2010

Tzounopoulos, T., Kim, Y., Oertel, D., and Trussell, L. O. (2004). Cell-specific, spike timing-dependent plasticities in the dorsal cochlear nucleus. Nat. Neurosci. 7, 719-725. doi: 10.1038/nn1272

Voigt, H. F., and Young, E. D. (1980). Evidence of inhibitory interactions between neurons in dorsal cochlear nucleus. J. Neurophysiol. 44, 76-96.

Voigt, H. F., and Young, E. D. (1990). Cross-correlation analysis of inhibitory interactions in dorsal cochlear nucleus. J. Neurophysiol. 64, 1590-1610.

Wickesberg, R. E., and Oertel, D. (1988). Tonotopic projection from the dorsal to the anteroventral cochlear nucleus of mice. J. Comp. Neurol. 268, 389-399. doi: $10.1002 / \mathrm{cne} .902680308$

Winter, I. M., and Palmer, A. R. (1995). Level dependence of cochlear nucleus onset unit responses and facilitation by second tones or broadband noise. J. Neurophysiol. 73, 141-159.

Wu, S. H., and Oertel, D. (1987). Maturation of synapses and electrical properties of cells in the cochlear nuclei. Hear. Res. 30, 99-110. doi: 10.1016/03785955(87)90187-0

Xie, R., and Manis, P. B. (2013). Target-specific IPSC kinetics promote temporal processing in auditory parallel pathways. J. Neurosci. 33, 1598-1614. doi: 10 1523/JNEUROSCI.2541-12.2013

Yang, H., and Xu-Friedman, M. A. (2008). Relative roles of different mechanisms of depression at the mouse endbulb of Held. J. Neurophysiol. 99, 2510-2521. doi: 10.1152/jn.01293.2007

Zhang, S., and Oertel, D. (1993). Tuberculoventral cells of the dorsal cochlear nucleus of mice: intracellular recordings in slices. J. Neurophysiol. 69, 1409-1421.

Zhang, S., and Oertel, D. (1994). Neuronal circuits associated with the output of the dorsal cochlear nucleus through fusiform cells. J. Neurophysiol. 71, 914-930.

Zhou, M., Tao, H. W., and Zhang, L. I. (2012). Generation of intensity selectivity by differential synaptic tuning: fast-saturating excitation but slow-saturating inhibition. J. Neurosci. 32, 18068-18078. doi: 10.1523/jneurosci.3647-12. 2012

Conflict of Interest Statement: The authors declare that the research was conducted in the absence of any commercial or financial relationships that could be construed as a potential conflict of interest.

Received: 05 April 2014; accepted: 18 June 2014; published online: 04 July 2014.

Citation: Sedlacek M and Brenowitz SD (2014) Cell-type specific short-term plasticity at auditory nerve synapses controls feed-forward inhibition in the dorsal cochlear nucleus. Front. Neural Circuits 8:78. doi: 10.3389/fncir.2014.00078

This article was submitted to the journal Frontiers in Neural Circuits.

Copyright (C) 2014 Sedlacek and Brenowitz. This is an open-access article distributed under the terms of the Creative Commons Attribution License (CC BY). The use, distribution or reproduction in other forums is permitted, provided the original author(s) or licensor are credited and that the original publication in this journal is cited, in accordance with accepted academic practice. No use, distribution or reproduction is permitted which does not comply with these terms. 